\title{
Assessment and mapping of water erosion by the integration of the Gavrilovic "EPM" model in the Inaouene watershed, Morocco
}

\author{
Laaraj Marouane ${ }^{1}$, Benaabidate Lahcen ${ }^{1}$ and Mesnage Valérie ${ }^{2}$ \\ ${ }^{1}$ Laboratory of Functional Ecology and Environment Engineering, University of Sidi Mohamed Ben Abdellah, Fez, Morocco \\ ${ }^{2}$ Continental and Coastal Morphodynamics Laboratory (M2C), University of Rouen-NORMANDY (France)
}

\begin{abstract}
Water erosion is one of the main causes of soil degradation around the world. In Morocco, In Morocco, the watersheds have very significant soil wastes, related to various phy sical and anthropic factors. The Oued Inaouene watershed is concerned because of its location in the eastern part of the Saïs basin, between the Middle Atlas and the Pre-Rif, where water erosion is more accentuated. This basin covers a total area of $3597.13 \mathrm{Km}^{2}$ and it is marked by a semi-arid climate with relatively abundant $(989.68 \mathrm{~mm})$, irregular rainfall and strong anthropic pressure. This will have an impact of overexploiting natural resources in general and soils in particular. The excessive use of agricultural land has led to their fragility and aggravation of their susceptibility to erosion. These conditions, both natural and anthropic, have induced a rather intense erosive dynamic, which can be visible in its various forms, including gullying and landslides. The erosive dynamics leads progressively and certainly to impoverish the soils of the watershed and the silting of the dam Idris 1st located downstream of the Oued Inaouene, hence the interest of this study. The use of the "EPM" model for the estimation of soil losses ap proaches the severity of the erosive phenomenon. The average soil loss due to water erosion according to the model used is estimated at $53.34 \mathrm{t} / \mathrm{ha} / \mathrm{y}$ ear. The maximum losses are about $597.642 \mathrm{t} / \mathrm{ha} / \mathrm{yr}$ per plot. Total annual losses for the watershed are approximately $211084195 \mathrm{t} / \mathrm{yr}$. Furthermore, the analy sis of these results allowed, with the help of GIS, to determine the factors that control water erosion and which are, in order of importance: rainfall, slope, and soil sensitivity Soil protection. If anti-erosion measures aren't adopted in the threatened parts of the watershed, this will have serious consequences for the dam and water quality.
\end{abstract}

\section{Introduction}

The natural environment of Morocco has undergone decades of significant degradation [9], related mainly to the development of populations and the pressure they have applied on natural resources. One of the aspects of this deterioration is the water erosion of soils, which has accelerated alarmingly. It plays an important role in the planning and development of countries [3].

Indeed, this natural phenomenon accelerates depending on a set of natural parameters (topography, intense rainfall, soil erodibility, etc.) and anthropogenic (road infrastructure, crops on highly sloping land, intensive livestock, etc.).

Accelerated water erosion is associated with excessive runoff caused by human activities, which destabilize and weaken the soil, overgrazing, clearing of forests for domestic purposes, and to expand agricultural areas, and inappropriate farming techniques that can cause economic and environmental damage.

It is a key factor that should be taken into consideration by the managers in environmental sector. This is based on the fact that the consequences of this random and recurring phenomenon are present in many sectors.

Water erosion is also an important source of suspended solids. The excessive transport of these materials to the aquatic environment can lead to undesirable repercussions such as degradation accompanied by a decrease in bathymetry, which decreases water storage capacity in reservoirs at about $1 \%$ per year [8], and it contributes very strongly to the problem of silting up of ports.

The nature of suspended materials, their concentrations, and any pollutants they contain or carry affect water quality and disrupt aquatic life [15]. Sediment deposition reduces the depth available for navigation and increases the risk of flooding. Excessive sediment volume also has an impact on flora and fauna. Because of the disastrous effects, the phenomenon of erosion presents a high interest for the economic development of countries.

In this context, erosion modelling and mapping is now a priority for managers to identify areas at risk and implement relevant solutions. Large variety of models are employed to estimate soil erosion risk, they are classified as empirical and physical, and their 
application differs in relation to the required input data [20].

The integration of available methods with the latest spatialization techniques such as remote sensing and geographic information systems have reduced financial expenses and save time for the realization of the mapping of hazards and subsequent targeted, rapid and effective intervention.

In this context, this study aims to use the method of potential erosion (EPM) integrated into a Geographic Information System (GIS) quantify and map the water erosion danger in the Oued Inaouene watershed.

\section{Study environment:}

Geographically, the watershed upstreamof the Driss ler dam (Fig.1) is located in the North of Morocco in the eastern end of the Saïs basin, situated between the parallels $(33.84 \mathrm{~N} ; 34.58 \mathrm{~N})$ and meridians $(3.78 \mathrm{~W}$; 4.91W). In the North, limited by the Pre-Rif and in the South by the Middle Atlas, in the east by the Middle Moulouya, in the North-West of Morocco by the Upper Ouergha and in the south-west of country by that of the Upper Sebou [17].

The Inaouéne watershed is subdivided into three structuraldomains, with the musty hills of the Pre-Rif in the North, while in the south stand the mountains of the northern Middle Atlas and the Paleozoic Tazekka massif [16]. The soil cover of the Inaouene watershed is marked by soil groups proportional to the lithological group. There are two main types of soil: thin soils covering the high plateaus of the Pre-Rif and Middle Atlas, and thick soils covering the lowlands, such as, the river terraces of the Inaouene [14].

The vegetation cover develops in the North-East and South of the watershed, both elements act on the hydrographicalnetwork which clearly is more important on the North side than on the South side. The direction of flow of the Oued Inaouène is from East to West over a distance of $163.5 \mathrm{~km}$, from the confluence of the Oued Larbae and the Oued Lahdar to the confluence with the Oued Sebou. The study area characterized by elevations (Fig.1) that exceed $1981 \mathrm{~m}$ and an outlet of $155 \mathrm{~m}$; the NE and SE parts where the altitudes vary between 1068 and 1981 occupy nearly $16 \%$ of the watershed area. This part of the basin has very strong slope particularly the SE part which is described by the presence of the buttonhole of Tazekka (1980 meters), on the otherhand, the $\mathrm{W}$ part where the dominant slices of altitudes highlight low slopes. The climate is conditioned by the geomorphological features, it is semi-arid, cold in winter and hot in summer.

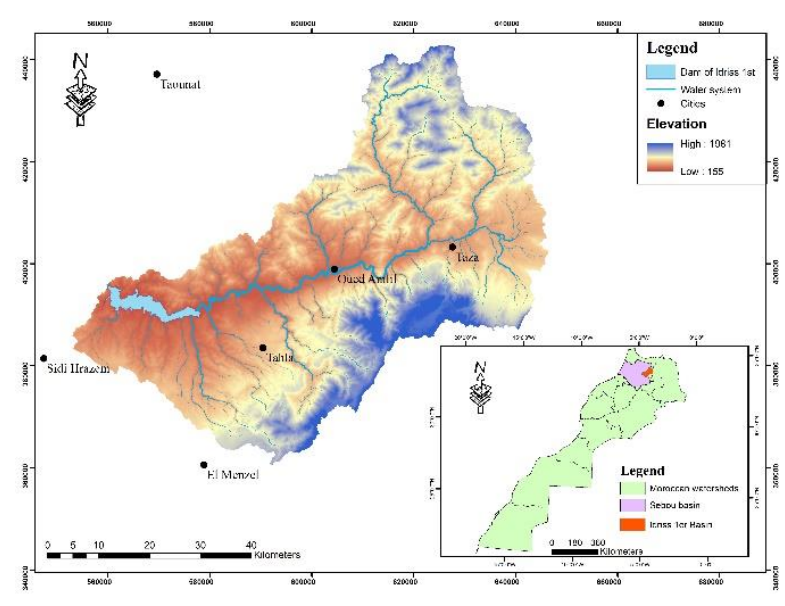

Fig1: Location of the study area

\section{The adopted method}

The EPM model "potential erosion method" [21], was created by Gavrilovic in the 1950s in the Morava River watersheds in Serbia [18]. Then the method was developed to predict annual soil erosion rates for a range of erosion types: erosion in gullies, slicks and ravines [11], for the management of erosion control practices. It was based on the mapping and combination of some parameters: soil erosion susceptibility, s lope, erosion status, soil protection, temperature and rainfall. This is different from the Universal Soil Loss Prediction Equation (USLE, RUSLE) that applies only to sheet erosion.

We are going to experiment with this model to estimate the erosion of the Oued Inaouene watershed, since all the data knowing the parameters of the model and the similarity of the physical conditions of the watershed are available. The application of the Gavrilovic model needs to map and integrate all the parameters necessary for the application of the empiric al model in the GIS, and to use spatial analysis techniques to evaluate soil loss, and estimate the weight of each factor and its overall impact on the soil. The parameters used studied by remote sensing, and the data collected from various sources, and then integrated into the GIS because it can process data easily and efficiently, it has become a useful tool for natural resource management and disaster research [23]. For this reason, researchers use this software as the main approach to evaluate and estimate soil erosion [1]. The work realized according to the steps recorded in the following flowchart (Fig.2). 


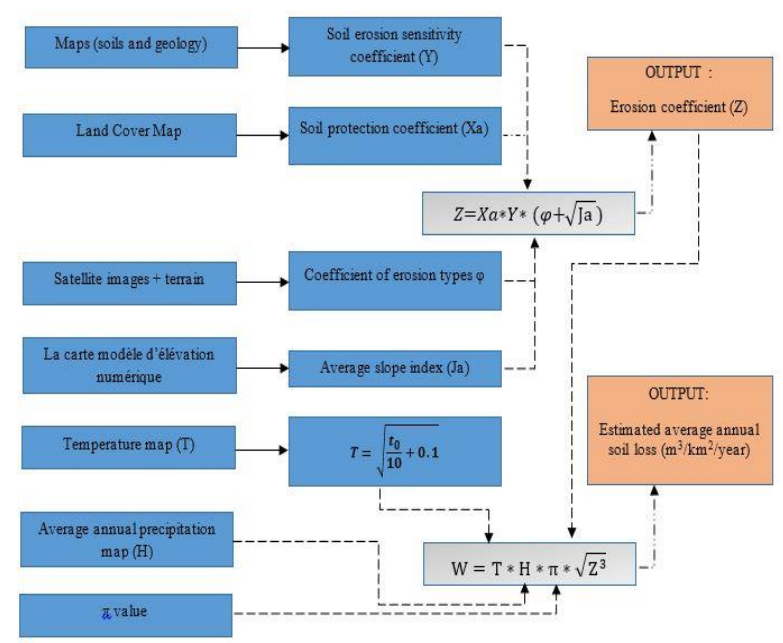

Fig2: Flow chart of the methodology used

\section{Parameterization of the EPM model factors}

The study of land loss (W) in the watershed of Oued Inaouene based on the four parameters of the EPM model "potential erosion method", it is determined as follows:

$$
W=T * H * \pi * \sqrt{Z^{3}}
$$

\subsection{Temperature coefficient (T) :}

Gavrilovic attempted to use temperature as an erosion factor in the EPM model, because thermal changes allow for the dismantling of components and rock formations. The value of the temperature can be based on the annual average temperature.

$T=\sqrt{\frac{t_{0}}{10}+0.1} t_{0}:$ Average annual temperature in $\left(\mathrm{C}^{\circ}\right)$

Due to the lack of temperature data in the Oued Inaouene basin, we used the data available on the "GlobalWeather" site, which covers many points in the watershed, with the important period "1990-2020".

The data provided by "Global Weather" are available on the website "https://globalweather.tamu.edu", a data site of the National Centers for Environmental Prediction (NCEP) and the Climate Prediction and Reanalysis System (CFSR), based on historical and operational records of observations, as well as a series of recently reprocessed observations from weather research institutions around the world.

The daily temperature data (maximum and minimum) of each station are in the file "CSV format", in units of $\left(\mathrm{c}^{\circ}\right)$. The stations in this file are distributed in matrix form, covering the area selected in the site. Then the calculation of the average annual temperature of each station was performed and using ArcGIS we were able to generate the map of average annual temperatures (Fig.3). This shows that the temperature decreases progressively from the lowest point in the basin, which corresponds to the station of the Idris $1 \mathrm{st}$ dam towards the station of Tainast in North, which is inversely proportional to the height.

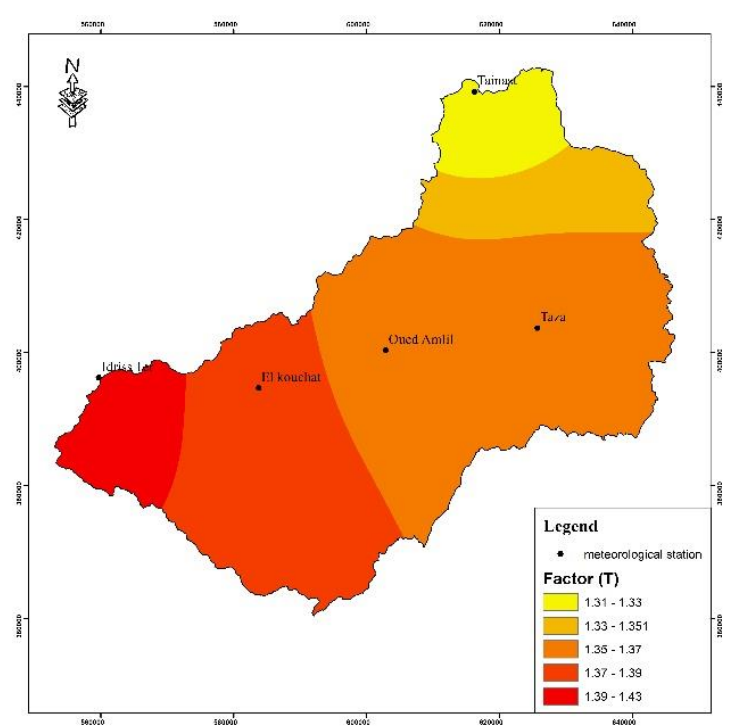

Fig.3: The temperature factor "T" of the Oued Inaouene watershed

\subsection{Average annual precipitation $(\mathrm{H})$ :}

The realization of the map (factor "H") of rainfall in the watershed of Oued Inaouene is also based on the data of the Sebou Hydraulic Basin Agency (ABHS) (Fig.4).

The high value is recorded in the southwestern part of the watershed, while the lowest value occurs at the station of Idris I dam, which is directly related to the change in altitude. Indeed, the value of the $\mathrm{H}$ factor is directly proportional to the value of monthly precipitation.

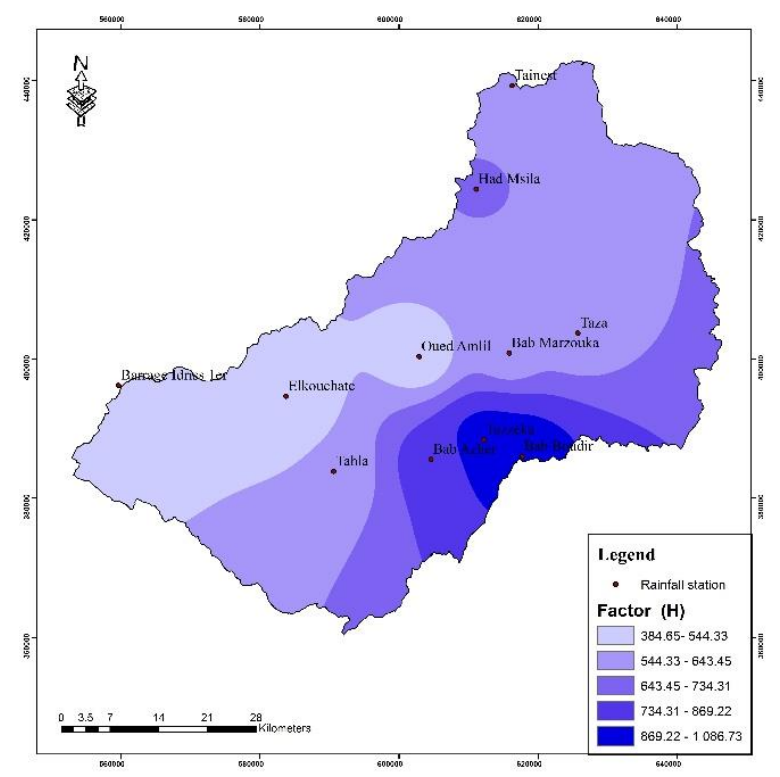

Fig. 4: Map of average annual precipitation $(\mathrm{H})$ of Oued Inaouene watershed

\subsection{Erosion coefficient $Z$ :}

The realization of this map requires the study of the following parameters: 


\subsubsection{Soil Protection Coefficient $\left(X_{a}\right)$ :}

The soil protection coefficient $\left(\mathrm{X}_{\mathrm{a}}\right)$ is directly associated with the vegetation cover and plays a significant role in reducing erosion by protecting the soil and increasing its permeability.

The values of $\left(X_{a}\right)$ vary according to the occupation of the soil by vegetation (Tab.1)

Table 1: (Xa) depending on land use by vegetation [22]

\begin{tabular}{|c|c|}
\hline Soil type & $\begin{array}{c}\text { Soil protection } \\
\text { coefficient (Xa) }\end{array}$ \\
\hline $\begin{array}{c}\text { Dense and medium-density } \\
\text { forests }\end{array}$ & $0.05-0.20$ \\
\hline $\begin{array}{c}\text { Pine forests and grasses } \\
\text { along the streams }\end{array}$ & $0.20-0.40$ \\
\hline Pastures and farms & $0.60-0.80$ \\
\hline Bare ground without cover & $0.80-1.00$ \\
\hline
\end{tabular}

To adjust the values of the soil protection factor index, we applied a vegetation cover factor (NDVI) from Landsat satellite data, and based on the method used by Chaaouan Jamal in 2015 [13] who aligned the results with the criteria he had fixed. By limiting the positive values of the vegetation cover index to 0.6 as the highest value, which represents areas of high vegetation density in the basin, the negative values were limited to -0.19 as the lowest value corresponding to bare land without cover.

After adjusting the vegetation cover coefficient, $X_{a}$ will be calculated according to the following equation:

$$
X_{a}=\left(X_{a} N D V I-0.61\right) *(-1.25)
$$

$X_{a}:$ Coefficient de protection du sol

$X_{a} N D V I$ : Adjusted vegetation cover factor, harmonization of soil protection index criteria

Figure 5 shows that the values of Xa between 0.4 and 0.8 covered the majority of the study area, representing pastures and farms, for the values of Xa $<0.4$ reflecting the existence of dense and medium forests, pine forests and herbs in the study area, is located along the rivers and south of the watershed at Jbel Tazekka.

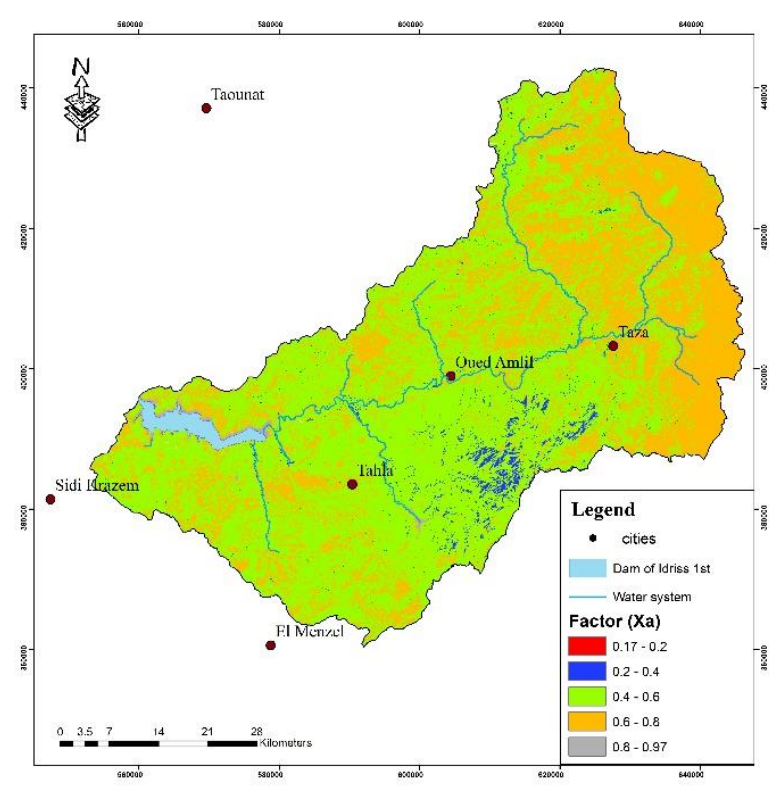

Fig. 5: Map of (Xa) values generated from the NDVI transformation

\subsubsection{Soil erosion coefficient $(Y)$ :}

The erosion factor $(\mathrm{Y})$ of a soil reflects its sensitivity to water erosion, it depends on intrinsic properties such as texture, structure and permeability. To determine the erosion coefficient for a soil, we use the relation of Wishmeier [10]:

$$
\begin{aligned}
Y=\left(2.1 * M^{1.14}\right. & * 10^{-4} *(12-a)+3.25 *(b-2) \\
& +2.5(c-3)) / 100
\end{aligned}
$$

$\mathrm{M}$ is calculated by the following equation:

$\mathrm{M}=(\%$ fine sand $+\%$ silt $) \times(100-\%$ clay $)$.

a: The percentage of organic matter.

$\mathrm{b}$ : The permeability code.

c: The code of structure.

The $\mathrm{Y}$ values for each soil unit were estimated using the soil map.

According to Gavrilovic the $\mathrm{Y}$ factor is classified by the following table:

Table 2: Soil type in function to Y [22].

\begin{tabular}{|c|c|}
\hline Soil type & Y factor \\
\hline Very high resistance and cohesion & $0.1-0.3$ \\
\hline Medium strength and cohesion & $0.3-0.5$ \\
\hline Low resistance & $0.5-0.6$ \\
\hline $\begin{array}{c}\text { Aggregate debris and coarse sediment } \\
\text { deposits }\end{array}$ & $0.6-0.8$ \\
\hline Fine sand, very low resistance soil & $>0.9$ \\
\hline
\end{tabular}

According to Gavrilovic's Table 2 and the values of the erosion coefficient in the Inaouene watershed (Fig. 6 ), the values vary between 0.22 and 0.4 as the highest value. It informs us that we are facing two types of soils: one of very high strength and cohesion (0.22-0.3) extends over $36 \%$ of the total area of the watershed, it is mainly concentrated in the north. The second type of soil of medium strength and cohesion $(0.3-0.4)$ is the most dominant, it is concentrated in the south of the basin with some points distributed along the Oued Inaouene. 


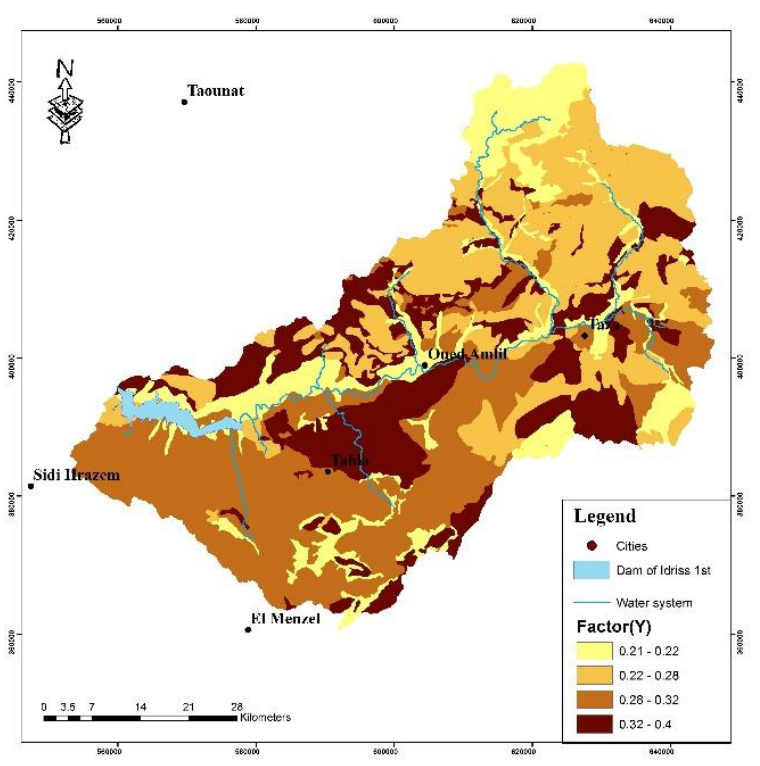

Fig. 6: Y factor map

\subsubsection{Coefficient de type et étendue de l'érosion $(\varphi):$}

The value of the erosion type coefficient $\boldsymbol{\varphi}$ nd its change depends on the size of the watershed. This factor determines and identifies the areas affected by erosion (rivers, streams, gullies, alluvial deposits or the entire watershed), which requires multiple visits to the watershed.

These values can be derived from fieldwork using observations of erosion development in the watershed and high-resolution satellite imagery.

In the absence of such images, the equation provided by Milevski [18] used to calculate this parameter, based on Landsat satellite images.

This index can be calculated by dividing the square root of the spectral band (TM3) by the maximum value of radiation (Qmax). This equation results in the spatial distribution of erodible areas as a function of the percentage of radiation, as the latter increases steadily with the intensity of erosion.

$$
\varphi=\sqrt{\frac{T M 3}{Q_{\max }}}
$$

We would like to point out that it is preferable to use images taken during the fall season, however, the band (TM3) should not be relied upon in areas with red soil because they reflect strong radiation even if the erosion effect can' t be clearly seen. In this case, the TM3 is replaced by the "brightness index of soil" to reduce the effect of red radiation produced by this type of soil. Based on the results of this equation that extract the values of the coefficient of erosion evolution from satellite images by automated methods. The highest values were registered in bad-land (0.6), while the lowest values were registered in green fields (0.3). It shows that there is a high degree of consistency between the descriptive criteria defined by Gavrilovic of the classical method, and the automated method that based on satellite images.
According to Gavrilovic there are several types of erosion that differ depending on $(\boldsymbol{\varphi})$ (Tab.3)

Table 3: Type of soil erosion based on $(\varphi)$. [22]

\begin{tabular}{|c|c|}
\hline Type coefficient and extent of erosion & Factor $(\boldsymbol{\varphi})$ \\
\hline Little erosion & $0.1-0.2$ \\
\hline $\begin{array}{c}\text { In-stream, erosion between } 20-50 \% \text { of the } \\
\text { watershed }\end{array}$ & $0.3-0.5$ \\
\hline $\begin{array}{c}\text { Erosion in rivers, ravines and alluvial } \\
\text { deposits }\end{array}$ & $0.6-0.7$ \\
\hline $\begin{array}{c}50-80 \% \text { of the watershed affected by } \\
\text { surface erosion and landslides }\end{array}$ & $0.8-0.9$ \\
\hline Entire watershed affected by erosion & 1.0 \\
\hline
\end{tabular}

According to Gavrilovic's table and figure 7, the basin has generally experienced two types of degradation: stream erosion, and erosion in rivers, gullies and alluvial deposits

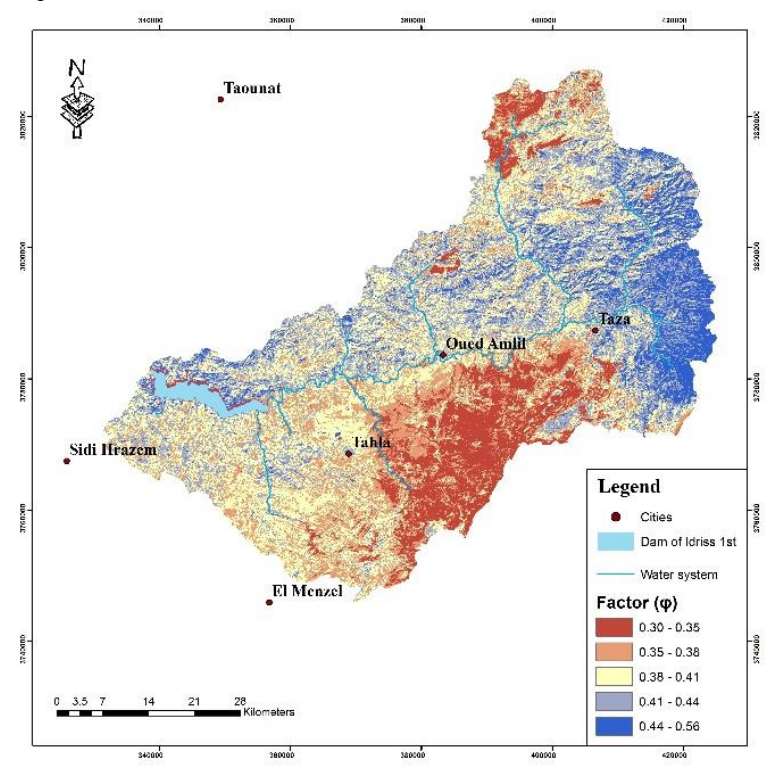

Fig. 7: Map of the factor $(\varphi)$ generated from the transformation of the LANDSAT satellite image.

\subsubsection{Slopes $\boldsymbol{J}_{\boldsymbol{a}}$ of the study area in (\%):}

A very important parameter in the EPM model is the slope. The increase in flow velocity due to the action of the slope causes strong erosion. The slopes can be calculated from the DTM file.

The analysis of the slope map (Fig.8) shows a dominance of the medium slope class (25-62), which is distributed throughout the watershed, although the steep slopes are located in the extreme North and South, this is related to the nature of the terrain, and the very irregular topography caused by the density and depth of the river network. 


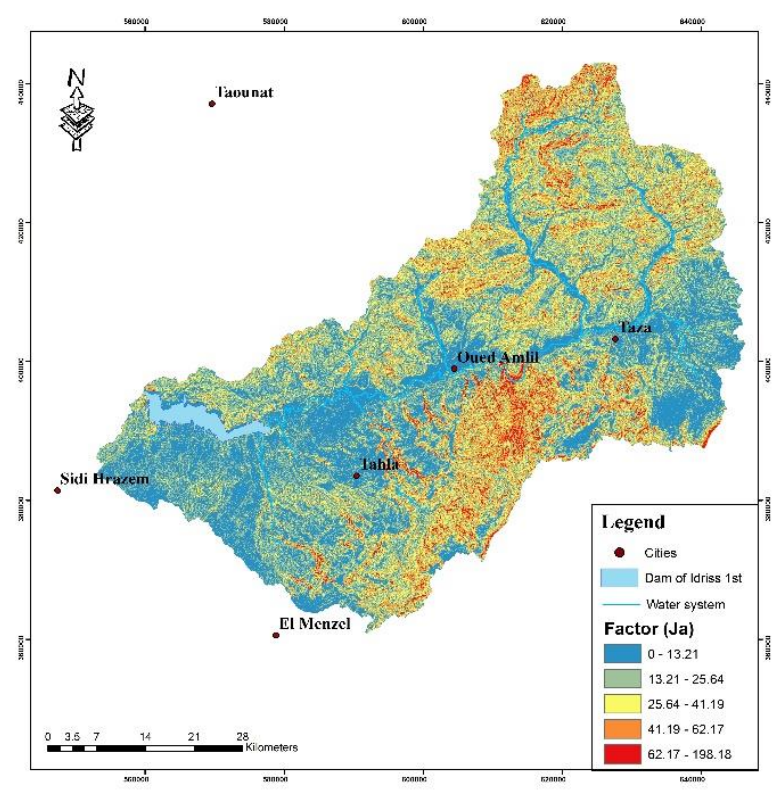

Fig.8: Slope map $J_{a}(\%)$

\subsubsection{Erosion coefficient (Z) :}

The erosion coefficient $(Z)$ is a non-dimensional parameter that indicates the severity or intensity of erosion in the watershed. Its value $(Z)$ defines the erosion class according to the Gavrilovic table (Tab.4).

$$
Z=X a * Y *(\varphi+\sqrt{J a})
$$

Xa: Soil protection coefficient of the watershed, referring to the protection of the soil by the vegetation cover, from the influences of atmospheric phenomena of erosive forces related to natural conditions.

Y: Coefficient of soil erodibility, indicates the sensitivity of soils to erosion depending on the geology of the watershed.

$\varphi$ : Coefficient of type and extent of numerical equivalent erosion of visible and clearly pronounced processes in the watershed

Ja: Average slope of the study area in (\%)

Table 4: Erosion class relative to (Z) [24]

\begin{tabular}{|c|c|}
\hline Erosion class & Value of (Z) \\
\hline Excessive erosion & $>1.51$ \\
\hline Severe erosion & $0.80-1.00$ \\
\hline Medium erosion & $0.41-0.80$ \\
\hline Slight erosion & $0.20-0.40$ \\
\hline Very slight erosion & $0.01-0.19$ \\
\hline
\end{tabular}

The combination of the erosive factors allowed us to evaluate the erosion coefficient at the level of the Inaouéne watershed, which leads to the following points:

-The distribution of slopes in the basin is proportional to the different types of possible erosion.

-Influence of soil type on erosion status, especially in areas characterized by low and medium slopes, and negligible in high slope areas.
-Lack of vegetation cover will result in high to very high erosion, which is also related to steep slopes and low soil resistance.

The analys is of the results in Figure 9 and Table 4 shows that most of the watershed suffers by the coefficient of severe and excessive erosion, concems $50 \%$ of the total area. It follows by the category of coefficient of average erosion, which also takes up an important percentage that reaches $40 \%$, the weak value of erosion is distributed along the Oued Inaouene, and in places in the south of the watershed.

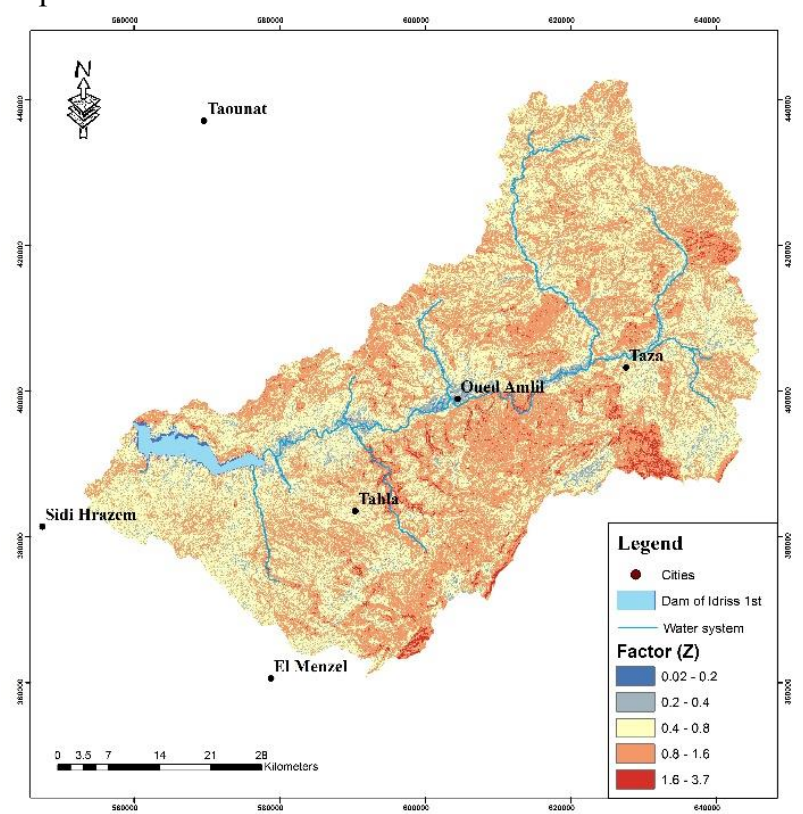

Fig.9: Erosion Coefficient Map (Z)

\section{5 estimation of soil losses according to the EPM model of Gavrilovic}

\subsection{Average annual volume of eroded sediment (W):}

After elaboration of all the maps representing the different factors of the EPM model, we obtain the average annual volume map (W) (Fig.10).

$$
W=T * H * \pi * \sqrt{\mathrm{z}^{3}}
$$

With: T: temperature coefficient $\left({ }^{\circ} \mathrm{C}\right)$.

$\mathrm{H}$ : annual precipitation (mm).

$\pi: 3,14$

$\mathrm{Z}$ : erosion coefficient. 


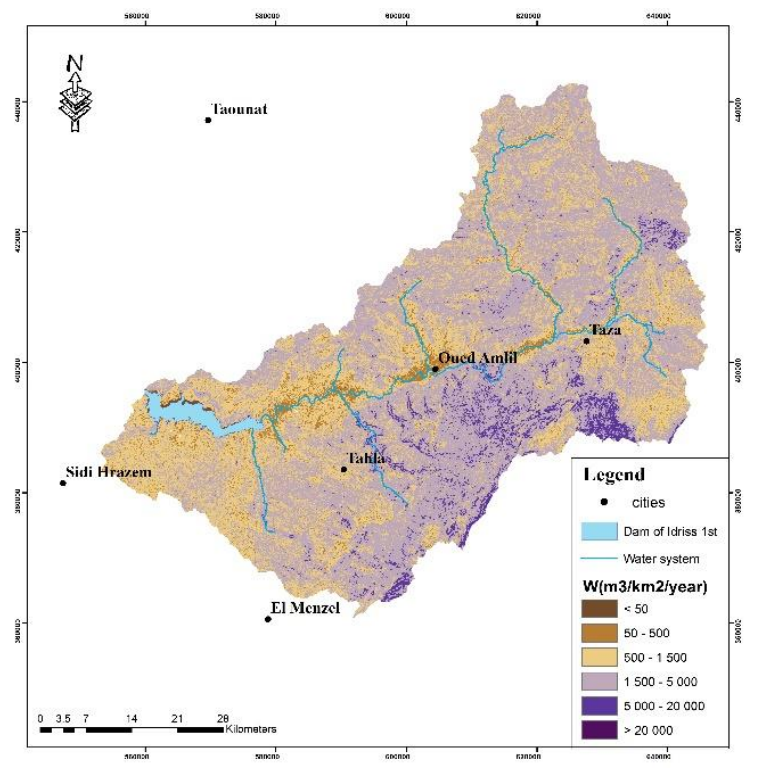

Fig 10: Annual volume of eroded sediment (W)

To estimate the total quantities (masses) of eroded sediments $\mathrm{G}$ (in ton $/ \mathrm{Km} 2 /$ year), we use the equation :

$$
\mathrm{G}=\mathrm{W} . \rho
$$

$\mathrm{W}$ : Average annual volume of eroded sediment (m3/km2/an)

$\rho$ : Density (ton $/ \mathrm{m} 3$ )

In particular, for the EPM, some modifications are necessary to express the result in the same units as RUSLE, which allows them to be compared with each other. The model assigns the average annual (compact) volume of loosened soil due to surface erosion W $\left(\mathrm{m}^{3} / \mathrm{yr}\right)$. This volume is multiplied by the specific soil value [17] (typically equal to $2.67 \mathrm{t} / \mathrm{m}^{3}$, ranging from 2.65 to $2.75 \mathrm{t} / \mathrm{m}^{3}$ ), resulting in an average annual soil loss ( $\mathrm{t}$ yr -1$)$. The result is the average annual soil loss per unit area $\left(\mathrm{t} / \mathrm{ha} / \mathrm{yr}\right.$ or $\left.\mathrm{t} / \mathrm{km}^{2} / \mathrm{yr}\right)$, also called mean annual specific erosion Wsp (Fig.11)

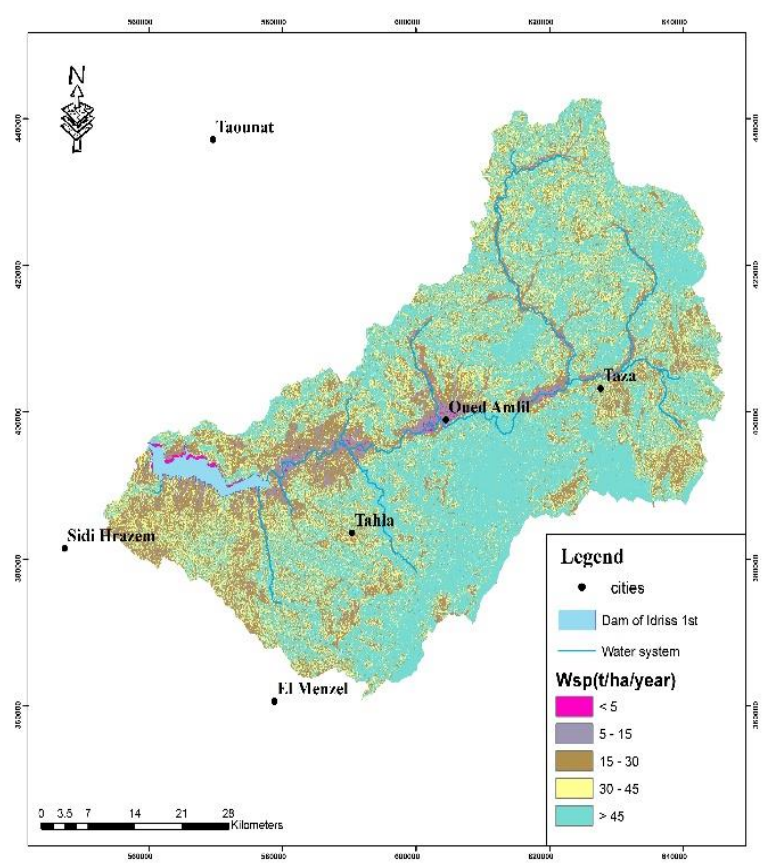

Fig. 11: Final map of erosion in the Oued Inaouene watershed
Table 5: Soil losses in the Oued Inaouene watershed

\begin{tabular}{|c|c|c|c|}
\hline $\begin{array}{c}\text { Classes } \\
(\mathbf{t} / \mathbf{h a} / \mathbf{y r})\end{array}$ & Intensity & $\begin{array}{c}\text { Area in } \\
(\mathbf{K m} \mathbf{2})\end{array}$ & $\begin{array}{c}\text { Area in } \\
\mathbf{( \% )}\end{array}$ \\
\hline$<5$ & Very low & 44.93 & 1.26 \\
\hline 15 & low & 211.06 & 5.93 \\
\hline 30 & Medium & 692.73 & 19.45 \\
\hline 45 & High & 782.02 & 21.96 \\
\hline$>45$ & Very High & 1830.50 & 51.40 \\
\hline
\end{tabular}

Combining the different factors that compose Gavrilovic's EPM equation, taking into account the numerical values of the seven factors, the map of soil losses due to water erosion is obtained, with an overall average is estimated at $53.34 \mathrm{t} / \mathrm{ha} /$ year. The maximu $\mathrm{m}$ and minimum losses per plot are $597.642 \mathrm{t} / \mathrm{ha} / \mathrm{yr}$ and $0.181 \mathrm{t} / \mathrm{ha} / \mathrm{yr}$ respectively.

The rate of erosion varies from one area of the watershed to another, depending on the influence of different physicaland anthropogenic factors that control the erosive dynamics. For reasons of map readability, these units are grouped into five classes (Fig. 11 and Table 5).

Land losses above $45 \mathrm{t} / \mathrm{ha} /$ year come from $51.40 \%$ of the watershed area located in the North and South central part of the watershed. It indicates the high propagation of the phenomenon. The low to very low intensity class (soil losses of less than $15 \mathrm{t} / \mathrm{ha} / \mathrm{year}$ ) covers a very little proportion of the study area $(7.19 \%)$ and is located in the Oued Inaouene and to the west of the basin near to the Idris $1 \mathrm{er}$ dam, and $41.41 \%$ of the total area studied has losses of between 30 and 45 $\mathrm{t} / \mathrm{ha} /$ year.

These values of soil losses are close to the results obtained by various researchers who have worked in northern Morocco. These studies have found erosion rates as high for instance $65 \mathrm{t} / \mathrm{ha}$ /year was estimated at the level of the Nakhla watershed [5], and 55.35 $\mathrm{t} / \mathrm{ha} /$ year at the level of Oued Boussouab in the eastem Prérif [4], $46.1 \mathrm{t} / \mathrm{ha} /$ year in the northeast at Oued Tlata [6] and $49.59 \mathrm{t} / \mathrm{ha} /$ year for the basin of Oued Larbaa and $43.68 \mathrm{t} / \mathrm{ha} /$ year on average for the catchment area of Oued Beni Boufrah, Central Rif [7]. On the other hand, the study conducted in the Middle Atlas as that of Hili [2] whose objective was also to estimate the erosion of a watershed Oued Amlil. The erosion obtained varies between 3.3 and $35 \mathrm{t} / \mathrm{ha} /$ year, with the maximum loss occupying $22 \%$ of the surface area.

\subsection{The weight of Erosion Factors on Soil Losses}

Empirical models are based on the relationship between a variable measured or evaluated through regression analysis. The unequal distribution of soil losses in the watershed results from the high variability in the impact of each erosion factor. Statistical relationships between the different factors and erosive dynamics show fairly significant trends. 
Table 6: Correlation matrix between soil losses and erosion parameters

\begin{tabular}{|c|c|c|c|c|c|c|c|c|}
\hline Layer & EPM & $\mathrm{T}$ & $\mathrm{H}$ & Z & $Y$ & $\varphi$ & Xa & $\mathrm{Ja}$ \\
\hline EPM & - & $\frac{\vec{J}}{n}$ & $\frac{8}{\stackrel{0}{0}}$ & 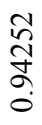 & 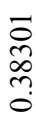 & $\frac{\stackrel{\Re}{+}}{\stackrel{\infty}{+}}$ & \begin{tabular}{l}
$\infty$ \\
0 \\
$\infty$ \\
\multirow{0}{0}{} \\
$\dot{0}$
\end{tabular} & $\frac{\infty}{\stackrel{\infty}{0}}$ \\
\hline $\mathrm{T}$ & $\begin{array}{l}\vec{J} \\
\stackrel{n}{7} \\
\dot{0}\end{array}$ & - & 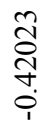 & 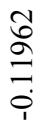 & 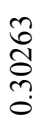 & $\begin{array}{l}\bar{T} \\
\text { Oे } \\
0 \\
0 \\
0\end{array}$ & $\begin{array}{l}0 \\
\circ \\
0 \\
0 \\
0 \\
0\end{array}$ & 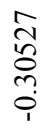 \\
\hline $\mathrm{H}$ & $\begin{array}{l}\stackrel{\circ}{0} \\
\stackrel{0}{\stackrel{0}{0}} \\
\stackrel{0}{0}\end{array}$ & 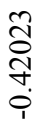 & - & $\begin{array}{l}\overline{0} \\
\text { ते } \\
\text { הิ } \\
0\end{array}$ & $\begin{array}{l}+ \\
\frac{2}{n} \\
0 \\
0\end{array}$ & $\begin{array}{l}\circ \\
n \\
2 \\
\text { กิ } \\
i\end{array}$ & 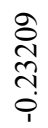 & 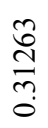 \\
\hline Z & 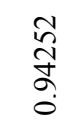 & 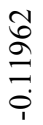 & 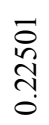 & - & $\begin{array}{l}\infty \\
\text { నे } \\
\text { ஸे }\end{array}$ & \begin{tabular}{l}
0 \\
\multirow{0}{0}{} \\
0 \\
0 \\
0
\end{tabular} & 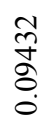 & $\frac{n}{\tilde{n}}$ \\
\hline Y & $\begin{array}{l}\overrightarrow{0} \\
\infty \\
\infty \\
\\
0\end{array}$ & $\begin{array}{l}\text { రె } \\
\text { ర్ } \\
\text { లె. } \\
0\end{array}$ & \begin{tabular}{l}
\multirow{2}{N}{} \\
$\hat{n}$ \\
0 \\
0
\end{tabular} & $\begin{array}{l}\text { के } \\
\text { ஸे }\end{array}$ & - & $\begin{array}{l}\stackrel{+}{2} \\
\stackrel{\infty}{0} \\
\frac{1}{0}\end{array}$ & 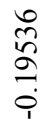 & \begin{tabular}{l}
0 \\
\multirow{7}{0}{} \\
0 \\
0 \\
0
\end{tabular} \\
\hline$\varphi$ & $\begin{array}{l}\frac{O}{8} \\
\frac{\infty}{0} \\
i\end{array}$ & 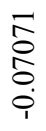 & 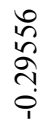 & \begin{tabular}{l}
$\hat{\infty}$ \\
\multirow{0}{0}{} \\
$\stackrel{0}{0}$ \\
$\dot{0}$
\end{tabular} & 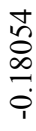 & - & $\frac{n}{n}$ & 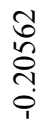 \\
\hline $\mathrm{Xa}$ & $\begin{array}{l}\infty \\
0 \\
\stackrel{0}{0} \\
\stackrel{\Xi}{0} \\
0\end{array}$ & 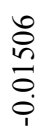 & 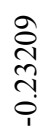 & \begin{tabular}{l}
$\tilde{O}$ \\
\multirow{2}{*}{} \\
$\stackrel{0}{0}$ \\
$\dot{0}$
\end{tabular} & $\begin{array}{l}0 \\
\\
2 \\
\stackrel{0}{0} \\
i\end{array}$ & $\underset{n}{n}$ & - & $\begin{array}{l}\stackrel{\infty}{N} \\
\stackrel{\sim}{\sim} \\
\stackrel{0}{0}\end{array}$ \\
\hline $\mathrm{Ja}$ & $\frac{2}{\frac{\infty}{0}}$ & 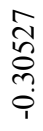 & 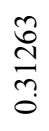 & $\frac{n}{\hat{\sigma}}$ & 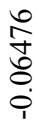 & 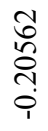 & $\frac{\infty}{N}$ & - \\
\hline
\end{tabular}

Table 6, allows to notice the strong correlation between the Wsp map and the erosion coefficient which is 0.94 . The most influential factor in this coefficient is the slope, which seems to be the most decisive in the erosive dynamics with a correlation coefficient of about $0.71(74.79 \%)$, and then the sensitivity of the soil occupies the second rank $39.84 \%$. Then we find the precipitation, which presents an important correlation of the order of 0.43 with a percentage of $35.37 \%$, on the other side the factor of the temperature with negative correlation to the erosion map Wps. The precipitation factor is itself more related to the slope with a correlation coefficient of 0.31 while temperatures are correlated well with soil erosion coefficient 0.33 .

\section{Conclusion:}

The implementation of Gavrilovic's EPM equation using a geographic information system(GIS) allowed for a quantitative estimation of soil losses in the Inaouene watershed upstream of the Idris I dam.

The study shows that average soil losses are estimated at $53.34 \mathrm{t} / \mathrm{ha} / \mathrm{yr}$ with a maximum of $597.642 \mathrm{t} / \mathrm{ha} / \mathrm{yr}$ per plot concentrated in the Sorth and South-central part of the basin.
The analysis of the results of this model allowed to establish the decisive causal factors that control water erosion and which are, in order of importance, rainfall, slope, soil sensitivity, Soil Protection

\section{References}

1. A. Belasri, Lakhouili A (2016) Estimation of soil erosion risk using the Universal Soil Loss Equation (USLE) and Geo-Information Technology in Oued El Makhazine Watershed, Morocco. Journal of Geographic Information System, 8, pp. 98-107, https://doi.org/10.4236/jgis .2016.81010

2. A. Hili, El Khalki Y, Reddad H, Gartet J, AbahrourM (2020) Comparais on des résultats de l'approche PAP/CAR et le modèle USLE dans la cartographie et l'estimation qualitative de l'érosion hydrique dans le bassin versant de l'Oued Amlil. Papeles de Geografía, 66 pp. 138-150. ISSN: 1989-4627. DOI: https://doi.org/10.6018/geografia.415511

3. A Raissouni, Khali Issa L, moussadek R, Mrabet R, El Arrim A. (2011). Érosion hydrique et transferts des matières vers les zones côtières méditerranéennes. Cas du bassin de l'oued Khmiss (Rif nord occidental. Maroc). Coastal and Maritime Mediterranean Conference. EDITION 2, TANGER, MAROC. http://www.paralia.fr

4. A. Sadiki (2004). Utilisation d'un SIG pour l'évaluation et la cartographie des risques d'érosion par l'Equation Universelle de Perte en Sol dans le Rif oriental (Maroc) : cas du bassin versant de l'Oued Boussouab. Bull. Inst Sci. Rabat, sec. Sci. Terre 26, 69-79.

5. A. Tribak, El Garouani A, Abachour M (2012) Water erosion in tertiary marl series of the Oriental Prérif (Morocco): agents, processes and quantitative evaluation. Rev. Mar. Sci. Agron. Vét. 1, 47-52.

6. A. Zahnoun, A1 Karkouri J. (2020). Estimation \& Cartography the Water Erosion by Integration of the Gavrilovic "Epm" Model using a Gis in the Mediterranean Watershed: Oued Tleta (Western Rif, Morocco). European Journal of Scientific Research. ISSN 1450216X / 1450-202X Vol. 155 No3. Pp.265 278. http://www. europeanjournalofscientificresearch.com

7. A. Zahnoun A, Al Karkouri J. (2016). Cartographie des risques d'erosion hydrique par l'application du modele "epm" de gavrilovic a l'aide d'un sig dans un bassin versant mediterraneen : Oued Beni Boufrah, Rif central. 3ème Edition du Colloque International des utilisateurs du SIG. The 3rd International conference of GIS User. Oujda 22-23

8. C. Fayas, Abeysingha N, Nirmanee K, Samaratunga D, Mallawatantri A (2019) Soil 
Loss Estimation Using Rusle Model to Prioritize Erosion Control in KELANI River Basin in Sri Lanka. International Soil and Water Conservation Research Volume 7, Issue 2, pp.130-137 https://doi.org/10.1016/j.is wcr.2019.01.003

9. D. El hafid, Akdim B (2018) Quantification de l'érosion hydrique en utilisant le modèle Rusle et déposition intégrée dans un SIG. Cas $\mathrm{du}$ bassin versant de l'oued Isly (Maroc Oriental). European Scientific Journal, edition Vol.14, No.5 ISSN : 1857-7881 (Print)e-ISSN 1857-7431. https://doi.org/10.19044/esj.2018.v14n5p 373

10. H. Wischmeier W, Smith D D. (1978). Smith Predicting rainfall erosion losses guide for conservation planning Science, U.S. Dept. of Agriculture. Agric. Handbook, Washington, D.C., $537 \mathrm{p}$.

11. I. Blinkov, Kostadinov S. (2010). Applicability of various Erosion Risk Assessment Methods for Engineering Purposes. DOI : 10.13140/2.1.4762.7849

12. I. Milevski. (2008): Estimation of Soil Erosion Risk in the Upper part of Bregalnica Watershed Republic of Macedonia, Based on Digital Elevation Model and Satellite Imagery, 5th ICGIS 2008, Istanbul.

13. J. Chaaouan .(2015). Estimation of water erosion in the Oued Amzaz watershed using an EPM model. In book: Use of remote sensing and geographic information systems in the study of erosion in the central rif Amzaz basin as a model. Edition: 1 Chapter: 14 Editors: FLS

14. J. Naoura. Caractérisation hydrologique et qualitative des eaux de surface du bassin versant du haut Inaouene (2012). PhD diss. Sidi Mohamed Ben Abdellah University of Fez.

15. L. Khali Issa, Lech-Hab K, Raissouni A, El Arrim A. (2016). Quantitative Mapping of Soil Erosion Risk Using GIS/USLE Approach at the Kalaya Watershed (North Western Morocco). J. Mater. Environ. Sci. 7 (8). 27782795. ISSN : 2028-2508 CODEN: JMESC.

16. L. Mesrar. Caractérisation géochimique, minéralogique, technologique et nanotechnologique des marnes miocènes du couloir sud rifain (Fès Taza) : études et valorisations (2013). PhD diss. Sidi Mohamed Ben Abdellah University of Fez.

17. M. Laaraj, Benaabidate L, Mesnage V. (2020). Ass essment of Inaouene River Pollution for Potable Water Supply, Northern Morocco. Journal of Ecological Engineering. Volume 21, Issue 7, pages 68-80. https://doi.org/10.12911/22998993/125450

18. N. Dragicevic , Karleusa B, Ozanic N. (2016). A review of the Gavrilovic method (Erosion
Potential Method) application. Grad-evinar. 68(9) : 715-725.

19. N. Efthimiou, Lykoudi E, Karavitis C. (2017). Comparative analys is of sediment yield estimations using different empirical soil erosion models. Hydrological Sciences Journal. Volume 62, 2017 - Issue 16. PP 2674-2694. https://doi.org/10.1080/02626667.2017.14040 68

20. S. Cuomo, Della Sala M (2015) Large-area analysis of soil erosion and landslides induced by rainfall: A case of unsaturated shallow deposits. Journal of Mountain Science, 12 (4). pp. 783-796. https://doi.org/10.1007/s 11629014-3242-7

21. S. Gavrilović. (1972). Inzenjering o bujic nimtokovima i eroziji. Izgradnja (special is sue), PPT, Beograd. Serbia.

22. S. Gavrilović. (1962). Medium application rate budget over erosion potential. Jaroslav Černi Institute, Belgrade, Serbia.

23. T. Gia Pham, Degenera J, Kappasa M (2018) Integrated universal soil loss equation (USLE) and Geographical Information System(GIS) for soil erosion estimation in A Sap basin: Central Vietnam. International Soil and Water Conservation Research. Volume 6, Issue 2, June 2018, Pp 99-110. https://doi.org/10.1016/j.iswcr.2018.01.001

24. Z. Gavrilovic. Stefanovic M, Milojevic M. and Cotric J. (2006). Erosion Potential Method, An Important Support for Integrate Water Ressource Management. Presented at XXIII Conference of the Danubian Countries on the Hydrological Forecasting and Hydrological Bases of Water Management, Bled, Slovenia. 